\title{
MDCT diagnosis of synchronous primary gastrointestinal tract carcinoma and other solid malignancies: case series study
}

\author{
Adel El-Badrawy ${ }^{1}$, Haytham Shebe ${ }^{2^{*}}$ (1) and Heba M. Abou El Atta ${ }^{3}$
}

\begin{abstract}
Background: The presentation of synchronous multiple primary tumors is rare. The aim of this report was to report an uncommon series of cases diagnosed with synchronous gastrointestinal tract carcinoma and other solid malignancies by multidetector computed tomography.

Case presentation: Our report included 34 patients with synchronous gastrointestinal tract carcinoma and other solid malignancies from November 2009 to September 2019. They were 14 men and 20 women (mean age, 65.5 year; range, 52-82 years). The highest number of GIT cases were colonic carcinomas detected in 70\% (24/34) of the patients. The most frequent extra-gastrointestinal primary malignancy sites were renal cell and breast carcinomas, $17.6 \%(6 / 34)$ of each.

Conclusions: Careful preoperative evaluation is recommended to detect this pattern of synchronous extra-gastrointestinal tumors. More reports of such cases should help to clarify the pathogenesis of this phenomenon and may lead to a new treatment strategy for synchronous gastrointestinal malignancy and other solid malignancies.
\end{abstract}

Keywords: Synchronous gastrointestinal tract carcinomas case report, Multidetector computed tomography, Primary solid malignancy

\section{Background}

The incidences of multiple primary malignancies have increased in recent years due to the increasing proportion of elderly patients in the general population, regular medical check-ups, and the increased number of cancer survivors [1].

Colorectal cancer (CRC) is the fourth most common malignancy and is the second leading cause of cancerrelated mortality in the USA. Accurate preoperative staging is the most critical step for determining the optimal treatment option and surgical planning for patients with CRC [2]. Gastric cancer has reduced prevalence but poor

\footnotetext{
*Correspondence: haythamshebel@gmail.com

${ }^{2}$ Radiology Department, Faculty of Medicine, Urology and Nephrology

Center, Mansoura University, El Gomhorea St., Mansoura, Egypt

Full list of author information is available at the end of the article
}

prognoses. To improve the treatment, early detection and better evaluation should be sought [3].

MDCT scanning is an accurate imaging modality for the evaluation of synchronous double malignancies [4]. Warren and Gates studied the multiple primary malignant tumors condition and established some diagnostic criteria in 1932, after reviewing over 1200 case reports. These criteria are still being accepted at present [5]. Multiple primary malignancies (MPMs) in a single patient are rare. In literature reviews, the overall incidence is between 0.73 and $11.7 \%$ [6]. Our report reviews the MDCT findings of a series of cases with synchronous primary gastrointestinal tract malignancy and other solid primary malignancies. original author(s) and the source, provide a link to the Creative Commons licence, and indicate if changes were made. The images or other third party material in this article are included in the article's Creative Commons licence, unless indicated otherwise in a credit line to the material. If material is not included in the article's Creative Commons licence and your intended use is not permitted by statutory regulation or exceeds the permitted use, you will need to obtain permission directly from the copyright holder. To view a copy of this licence, visit http://creativecommons.org/licenses/by/4.0/. 


\section{Case presentation}

This report was approved by the institutional research ethics review committee. Informed consent from the patient was waived. Our report included 34 patients with synchronous gastrointestinal tract carcinoma and other solid malignancies from November 2009 to September 2019-fourteen men and 20 women (mean age, 65.5 year; range, $52-82$ years).

The triphasic abdominal and whole-body CT scanning were performed using $64 \mathrm{MDCT}$ scanners (Brilliance 64; Philips Healthcare, Best, The Netherlands). MDCT diagnosed thirty-four patients with sixty-eight malignancies and pathologically proved to have primary gastrointestinal tract carcinoma with other primary malignant tumors. The highest number of GIT cases were colonic carcinomas detected in $70 \%(24 / 34)$ of the patients. The most frequent extra-gastrointestinal primary malignancy sites were renal cell and breast carcinomas, $17.6 \%(6 / 34)$ for each. The remaining types of tumors and their prevalence and their TNM staging are illustrated in Table 1 and Figs. 1, 2, 3 and 4. The main CT features of these tumors include the colonic and gastric carcinoma with irregular wall thickening, more than $10 \mathrm{~mm}$. Periampullary malignances diagnosed by pancreatic head mass with double duct signs. The main CT appearance of renal cell and hepatocellular carcinomas were enhancement in arterial phase, washout on portal and delayed phases. The breast carcinoma was soft tissue mass with speculated margins. The prostatic carcinoma was enlarged heterogeneous prostate with disruption of prostatic capsule. The urinary bladder carcinoma was diagnosed by localized irregular wall thickness, more than $10 \mathrm{~mm}$. The lymphoma was diagnosed with malignant lymphadenopathy. The ovarian carcinoma was diagnosed by cystic lesion with solid component and thick septae. The endometrial carcinoma was diagnosed by endometrial thickness, more than $18 \mathrm{~mm}$. The bronchogenic carcinoma was diagnosed by lung mass of about $25 \mathrm{~mm}$ with speculated margins and associated with ipsilateral mediastinal malignant lymphadenopathy. The thyroid carcinoma was diagnosed by thyroid mass of about $45 \mathrm{~mm}$ across with irregular margins and fine granular calcifications.

Warren and Gates criteria were applied to our report to identify extra-gastrointestinal primary malignancies [3]. Biopsy was done to exclude the possibilities of metastasis.

All primary gastrointestinal tract carcinoma and other synchronous malignancies were detected simultaneously except for one patient. This patient underwent a right mastectomy for breast carcinoma five months ago. During follow-up CT scanning, there was ascending colonic mass with regional malignant lymphadenopathy. This colonic mass proved pathologically as colonic carcinoma. Various details as patient gender, age at each tumor diagnosis, the primary site of origin, histopathology, and clinical-stage have been recorded (Table 1). The American Joint Committee on Cancer (AJCC) tumornode-metastasis (TNM) staging is a universally accepted staging system for cancer [7]. Therefore, it has become the staging system in our report. Barcelona Clinic Liver Cancer (BCLC) staging system is the most commonly used for the evaluation of hepatocellular carcinoma (HCC) [8]. Therefore, it has become the staging system for $\mathrm{HCC}$ in our report. Warren and Gates proposed the criteria of synchronous double primary malignancies are now generally accepted [5].

\section{Discussion}

Synchronous primary multiple malignancies are tumors that present simultaneously or within six months of one another [9]. The diagnostic criteria of double primary malignancies were those proposed by Warren and Gates [5]. These criteria are given as follows: (1) each tumor must present a definitive picture of malignancy; (2) each tumor must be separate; and (3) the probability of one being a metastasis of the other must be reasonably excluded. The last decade has experienced a steady increase in the incidence of multiple primary malignancies (MPM) due to improved diagnostic techniques and the aging of the population [10].

All sixty-eight malignancies in our report underwent needle biopsy and histopathological evaluation. This agrees with the previous report that confirms the pathological proof of synchronous primary solid malignancies and establishes the histological origin of the primary neoplasm [11]. Elderly age is a risk factor for developing second primary malignancies [12], which manifested with our result, as the mean age was 65.5 years.

Our report used Multidetector CT scanning, which has an accurate assessment for preoperative evaluation of gastrointestinal malignancies $[1,13-15]$ and other primary sites in different body parts [16-21].

Incidentally detected renal cell tumors are generally smaller in size. The incidence of its detection is steadily growing due to the widespread use of imaging modalities for other medical problems [22, 23]. This agrees with our results as all six patients with renal cell carcinoma are incidental.

The MDCT findings of renal cell and hepatocellular carcinomas in the multiple primary malignancies are similar to that of RCC and HCC-alone patients [4]. This agrees with our results as characteristic $\mathrm{CT}$ findings were detected in all six patients with renal cell carcinoma and four patients with hepatocellular carcinoma.

The incidences of primary intra-abdominal malignancies such as renal, hepatic, and pancreatic cancer were higher in the synchronous group than in other groups. 
Table 1 Characteristics of 34 patients with synchronous primary gastrointestinal tract carcinoma and other solid malignancies

\begin{tabular}{|c|c|c|c|c|c|c|c|c|c|c|}
\hline \multirow[t]{2}{*}{ Case no } & \multirow[t]{2}{*}{ Age/sex } & \multicolumn{4}{|c|}{ Colonic carcinoma } & \multicolumn{5}{|c|}{ Extra-colonic malignancy } \\
\hline & & \multicolumn{4}{|c|}{ TNM staging } & Site & \multicolumn{4}{|c|}{ TNM staging } \\
\hline \multicolumn{11}{|c|}{ Colonic carcinoma } \\
\hline 1 & $68 / F$ & $\mathrm{~T} 4 \mathrm{a}$ & N1b & MO & $\| I \mathrm{~B}$ & Renal & T1a & No & MO & I \\
\hline 2 & $68 / M$ & $\mathrm{~T} 4 \mathrm{a}$ & N1b & MO & $\| I I B$ & Renal & T1b & No & Mo & I \\
\hline 3 & $58 / M$ & T4a & $\mathrm{N} 2 \mathrm{~b}$ & MO & $\| I I C$ & Renal & T1a & NO & Mo & I \\
\hline 4 & $65 / F$ & $\mathrm{~T} 3$ & N1a & Mo & $\| I \mathrm{~B}$ & Renal & T1a & No & MO & I \\
\hline 5 & $67 / M$ & T4a & $\mathrm{N} 2 \mathrm{a}$ & MO & IIIC & Renal & $\mathrm{T} 1 \mathrm{~b}$ & NO & Mo & 1 \\
\hline 6 & $54 / F$ & $\mathrm{~T} 4 \mathrm{a}$ & $\mathrm{N} 2 \mathrm{~b}$ & MO & $\| I B$ & Breast & $\mathrm{T} 2$ & No & Mo & $\| \mathrm{A}$ \\
\hline 7 & $65 / F$ & T4a & $\mathrm{N} 2 \mathrm{~b}$ & M1C & IVC & Breast & $\mathrm{T} 2$ & No & Mo & $\| \mathrm{A}$ \\
\hline 8 & $60 / F$ & $\mathrm{~T} 4 \mathrm{~b}$ & NO & Mo & $\| C$ & Breast & \multicolumn{4}{|c|}{ Recurrent metastatic breast cancer } \\
\hline 9 & $65 / F$ & T4a & No & MO & $\| B$ & $\mathrm{HCC}$ & \multicolumn{4}{|c|}{$\mathrm{A}(\mathrm{BCLC}$ staging $)$} \\
\hline 10 & $66 / M$ & T3 & N1 & MO & $\| \mathrm{II}$ & $\mathrm{HCC}$ & \multicolumn{4}{|c|}{ C (BCLC staging) } \\
\hline 11 & $64 / F$ & $\mathrm{~T} 4 \mathrm{~b}$ & N1 & Mo & IIIC & $\mathrm{HCC}$ & \multicolumn{4}{|c|}{ C (BCLC staging) } \\
\hline 12 & $76 / \mathrm{M}$ & $\mathrm{T} 3$ & N2a & Mo & $\| I \mathrm{~B}$ & Prostate & T3a & No & MO & $\| \mathrm{IIB}$ \\
\hline 13 & $82 / \mathrm{M}$ & $\mathrm{T} 3$ & No & Mo & $\| \mathrm{A}$ & Prostate & $\mathrm{T} 2 \mathrm{C}$ & No & MO & $\| C$ \\
\hline 14 & $71 / \mathrm{M}$ & $\mathrm{T} 4 \mathrm{a}$ & NO & MO & $\| \mathrm{B}$ & Prostate & $\mathrm{T} 2 \mathrm{C}$ & NO & MO & $\| \mathrm{C}$ \\
\hline 15 & $52 / \mathrm{M}$ & $\mathrm{T} 3$ & $\mathrm{~N} 2 \mathrm{a}$ & MO & $\| I \mid B$ & UB & $\mathrm{T} 3 \mathrm{~b}$ & NO & MO & $\| I I$ \\
\hline 16 & $74 / \mathrm{M}$ & T3 & No & MO & $\| \mathrm{A}$ & UB & T3b & No & MO & $\| \mathrm{A}$ \\
\hline 17 & $52 / F$ & T3 & $\mathrm{N} 2 \mathrm{a}$ & M1a & IVA & Ovarian & \multicolumn{4}{|c|}{ Local recurrent } \\
\hline 18 & $65 / F$ & $\mathrm{~T} 3$ & $\mathrm{~N} 2 \mathrm{a}$ & M1a & IVA & Ovarian & \multicolumn{4}{|c|}{ I (FIGO staging) } \\
\hline 19 & $53 / F$ & $\mathrm{~T} 4 \mathrm{a}$ & No & Mo & $\| B$ & Endo & \multicolumn{4}{|c|}{ IB (FIGO staging) } \\
\hline 20 & $66 / F$ & $\mathrm{~T} 4 \mathrm{a}$ & N1 & MO & $\| \mathrm{IIB}$ & Endo & \multicolumn{4}{|c|}{ IIIC1 (FIGO staging) } \\
\hline 21 & $69 / M$ & $\mathrm{~T} 4 \mathrm{a}$ & N1 & M1a & IVA & $\mathrm{NHL}$ & \multicolumn{4}{|c|}{ III (Ann Arbor Staging) } \\
\hline 22 & $60 / F$ & $\mathrm{~T} 2$ & $\mathrm{~N} 2 \mathrm{a}$ & MO & $\| \mathrm{B}$ & $\mathrm{HD}$ & \multicolumn{4}{|c|}{ II (Ann Arbor Staging) } \\
\hline 23 & $68 / M$ & T4a & $\mathrm{N} 2 \mathrm{a}$ & Mo & IIIC & Thyroid & T3a & $\mathrm{N} 1 \mathrm{~b}$ & MO & $\|$ \\
\hline \multirow[t]{3}{*}{24} & $66 / F$ & $\mathrm{~T} 3$ & NO & Mo & $\| \mathrm{A}$ & Lung & $\mathrm{T} 1 \mathrm{C}$ & N2 & MO & $\| \mathrm{A}$ \\
\hline & Age/sex & \multicolumn{4}{|c|}{ Stomach } & \multicolumn{5}{|c|}{ Extra-gastric malignancy } \\
\hline & & \multicolumn{4}{|c|}{ TNM staging } & Site & TNM & & & \\
\hline Gastric car & & & & & & & & & & \\
\hline 25 & $65 / F$ & $\mathrm{~T} 3$ & No & Mo & $\| A$ & $\mathrm{HCC}$ & $\mathrm{B}(\mathrm{BC}$ & ging) & & \\
\hline 26 & $66 / F$ & $\mathrm{~T} 3$ & N3 & M1 & IV & Breast & $\mathrm{T} 4 \mathrm{~b}$ & $\mathrm{~N} 2 \mathrm{a}$ & MO & $\| I B$ \\
\hline 27 & $75 / F$ & T3 & N2 & MO & $\| B$ & Breast & T3 & $\mathrm{N} 1$ & MO & $\| I I A$ \\
\hline 28 & $66 / F$ & $\mathrm{~T} 4 \mathrm{a}$ & N3a & MO & IIIC & $\mathrm{NHL}$ & $\|(A r$ & or Stag & & \\
\hline 29 & $58 / \mathrm{M}$ & T3 & No & MO & $\| \mathrm{A}$ & $\mathrm{HD}$ & I (An & r Stagi & & \\
\hline 30 & $60 / F$ & T3 & No & M1 & IV & Endo & $\mathrm{lb}(\mathrm{F}$ & aging) & & \\
\hline & Age/sex & Peria & lary & & & Extra-pe & ullary & jnancy & & \\
\hline & & TNM & & & & Site & TNM & & & \\
\hline & & $T$ & $\mathbf{N}$ & $M$ & Stage & & $\bar{T}$ & $\mathrm{~N}$ & $M$ & Stage \\
\hline Carcinome & & & & & & & & & & \\
\hline 31 & $65 / F$ & $\mathrm{~T} 3 \mathrm{~b}$ & No & MO & $\| B$ & UB & $\mathrm{T} 2 \mathrm{~b}$ & No & MO & $\|$ \\
\hline 32 & $80 / \mathrm{M}$ & $\mathrm{T} 3 \mathrm{~b}$ & NO & MO & $\| B$ & UB & T3b & No & MO & $\| I I A$ \\
\hline 33 & $74 / M$ & $\mathrm{~T} 1$ & No & MO & IA & Renal & T1a & No & MO & 1 \\
\hline & Neuroendocrine & & & & & & & & & \\
\hline 34 & $64 / F$ & $\mathrm{~T} 2$ & NO & MO & $\|$ & Breast & $\mathrm{T} 4 \mathrm{~b}$ & $\mathrm{~N} 2 \mathrm{a}$ & MO & $\| \mathrm{A}$ \\
\hline
\end{tabular}

BCLC: Barcelona Clinic Liver Cancer staging classification, Endo.: Endometrial carcinoma, FIGO: the International Federation of Gynecology and Obstetrics, HCC: hepatocellular carcinoma, HD: Hodgkin disease, NHL: Non-Hodgkin lymphoma, RCC: renal cell carcinoma, UB: urinary bladder 


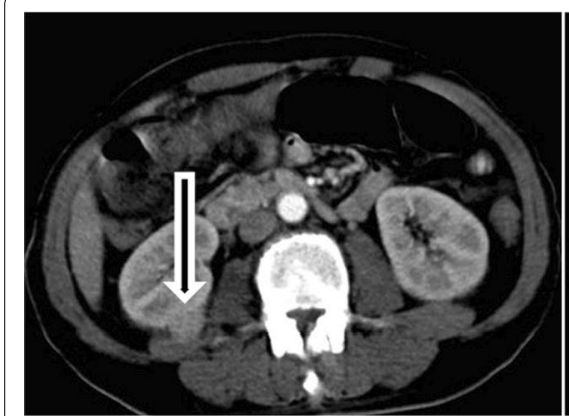

A

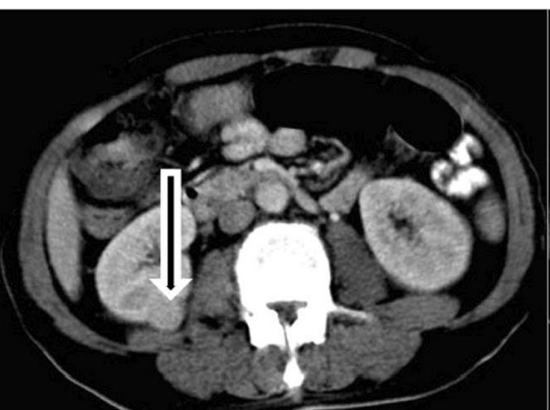

B

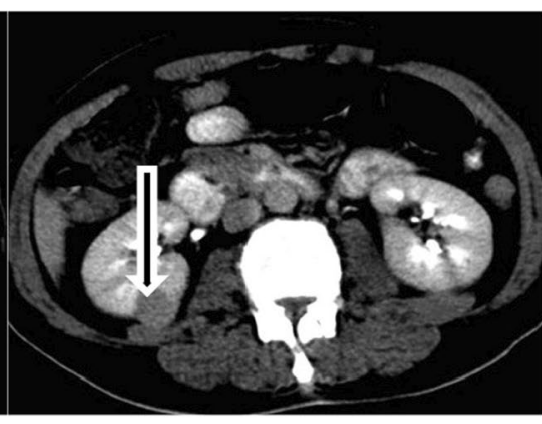

C

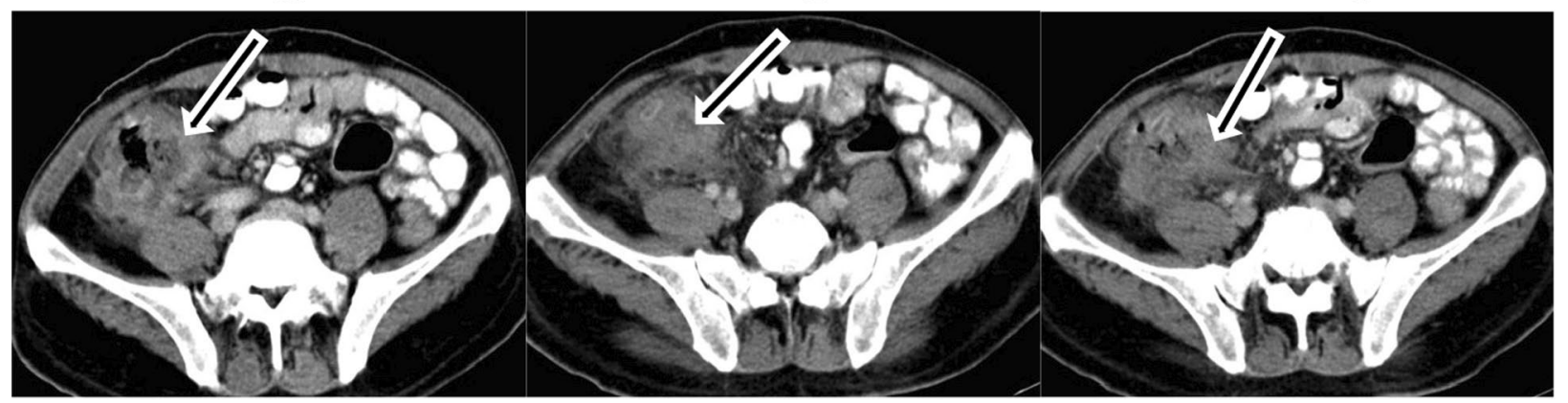

D

E

F

Fig. 1 A 58-year-old male presented with bleeding per rectum. MDCT scan revealed right renal mass (arrows). It revealed enhancement on arterial phase (A), washout on portal (B) and delayed phases (C). Pathologically proved RCC. (D-F) MDCT scan revealed caecal mass (arrows) pathologically proved colonic carcinoma
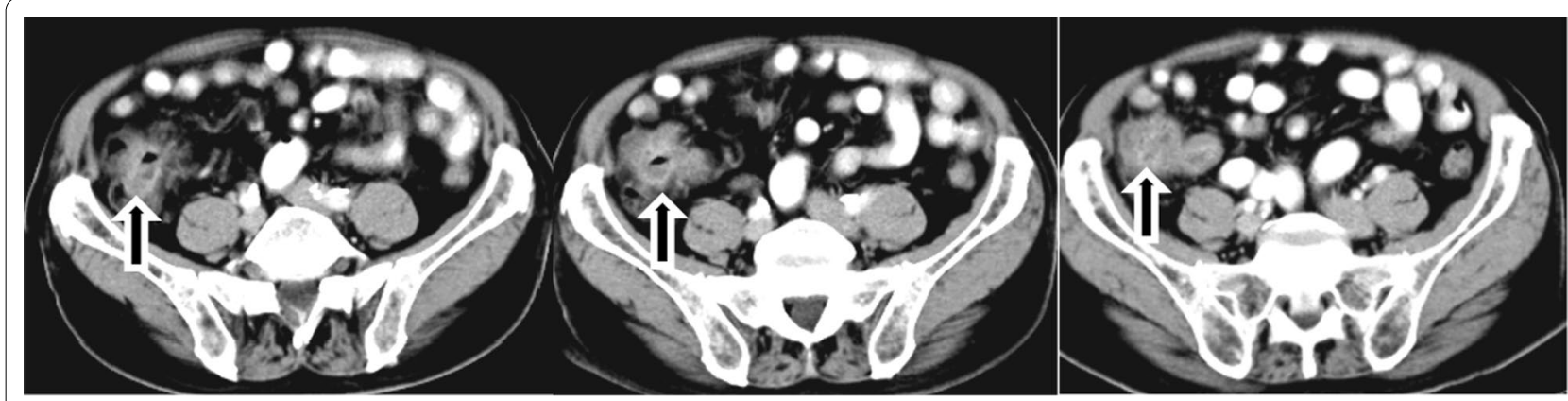

A

B

C

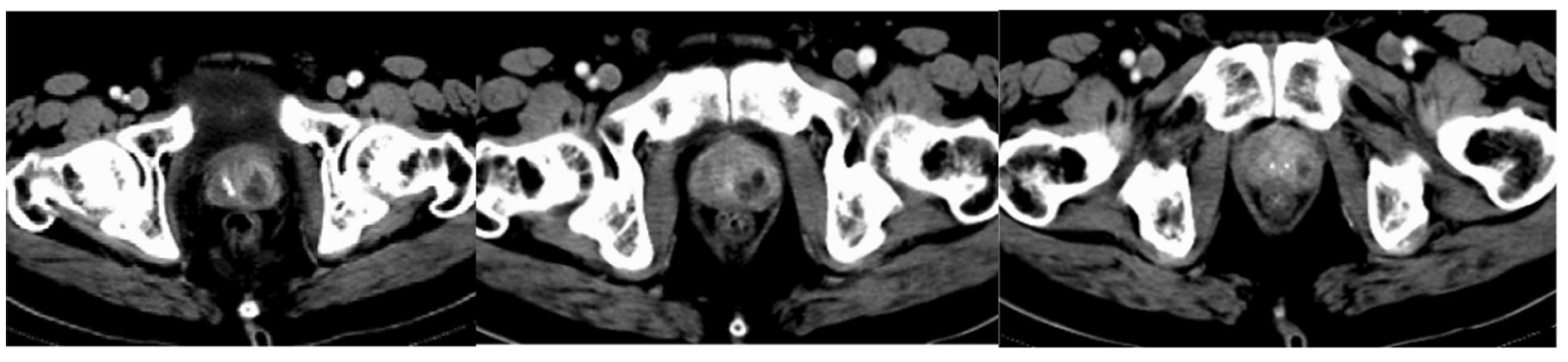

D

$\mathbf{E}$

F

Fig. 2 76-year-old male presented with follow-up during treatment for prostatic carcinoma. MDCT scan of pelvis revealed cecal mass (arrows)

$(\mathbf{A}-\mathbf{C})$ with prostate carcinoma proved by transrectal biopsy (arrows) (D-F) 


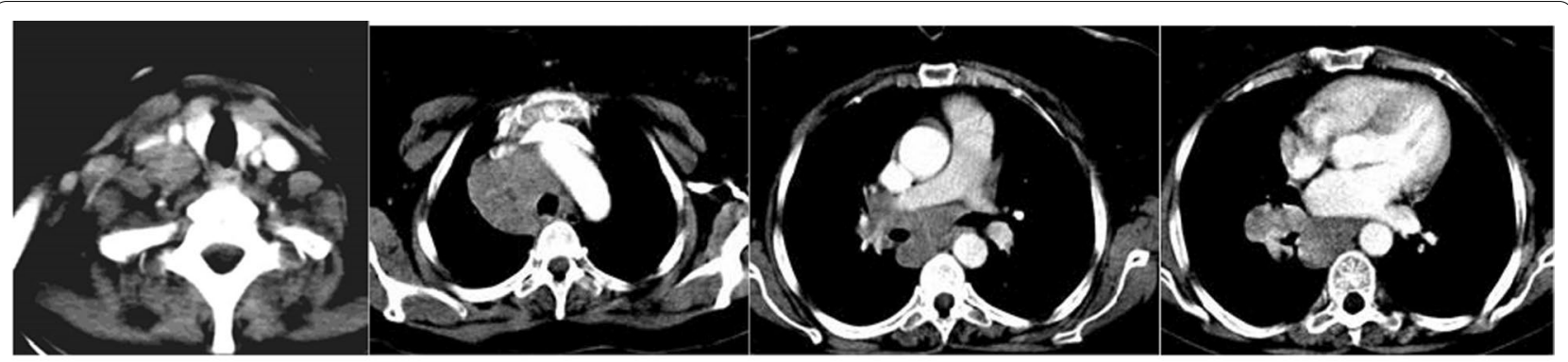

A

B

C

D

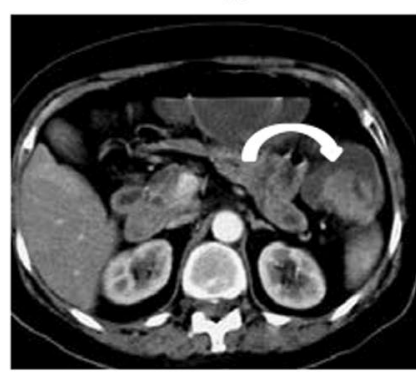

E

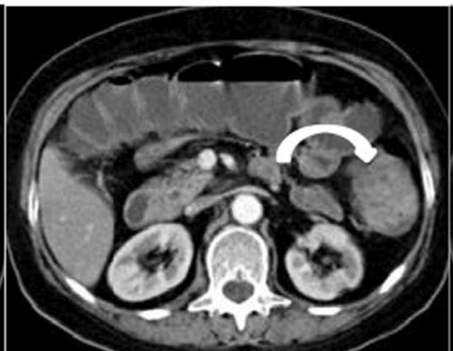

$\mathbf{F}$

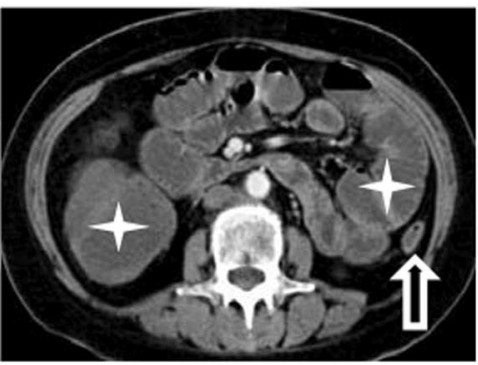

G

Fig. 3 60-year-old female presented with colonic obstruction. CT scan neck and chest revealed right lower cervical, mediastinal, right hilar and sub-carinal malignant lymphadenopathy (A-D). Biopsy revealed HD. CT scan abdomen (E, F) revealed splenic flexure cauliflower mass proved to be colonic carcinoma (curved arrows) (E, F). CT scan (G) revealed proximal intestinal obstruction (asterisks) with collapsed descending colon (arrow)

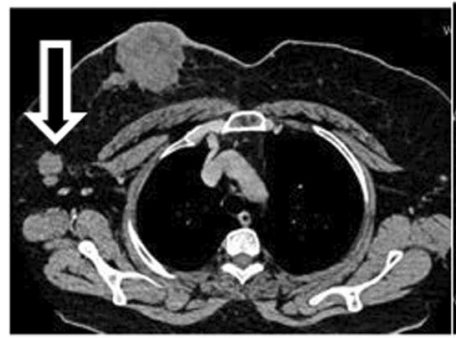

A

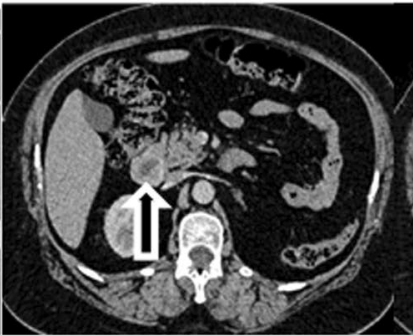

B

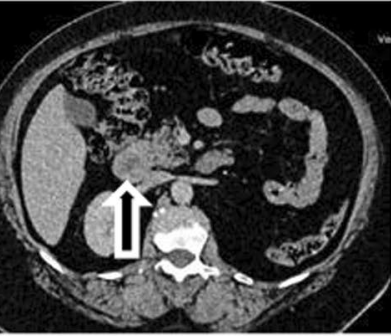

C

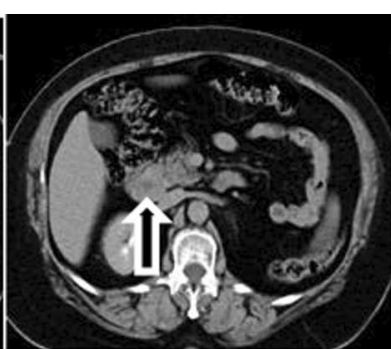

D

Fig. 4 64-year-old female presented with right breast pathologically proved carcinoma. MDCT scan (A) revealed right breast mass with right axillary malignant lymphadenopathy (arrow). MDCT scan (B-D) revealed periampullary mass (enhanced in arterial phase, washout in portal and delayed phases (arrows) (pathologically proved neuroendocrinal carcinoma)

Most primary synchronous malignancies were detected during the preoperative workup, which revealed most were located in the intra-abdominal cavity [24]. This is with our report as synchronous extra-gastrointestinal tract primary malignancies represent $70 \%$ of abdominal malignancies, as illustrated in Table 1 . The exact relationship between synchronous primary gastrointestinal tract malignancy and other primary malignancies remains unclear. It would be of clinical benefit to clarify what types of other primary malignancies occur in synchronous gastrointestinal tract malignancy.

\section{Conclusion}

In conclusion, Careful preoperative evaluation is recommended to detect this pattern of synchronous extragastrointestinal tumors. More reports of such cases should help clarify the mechanisms of this phenomenon and may lead to a new treatment strategy for synchronous gastrointestinal malignancy and other solid malignancies.

\section{Abbreviations}

CRC: Colorectal cancer; MPM: Multiple primary malignancies; AJCC: American Joint Committee on Cancer; MDCT: Multidetector CT; CT: Computed 
tomography; BCLC: Barcelona clinic liver cancer; RCC: Renal cell carcinoma; HCC: Hepatocellular carcinoma.

\section{Acknowledgements}

Not applicable.

\section{Authors' contributions}

AE was responsible for the idea, searching and collection of the data from the archiving system, in addition to writing the manuscript. HS was responsible for planning for the study design $\mathrm{CT}$, in addition to writing, reviewing, and submission of the manuscript. HA was responsible for obtaining the authorization for searching the archiving system with substantial involvement in the writing and reviewing the whole manuscript. All authors read and approved the final manuscript.

\section{Funding}

Nothing to be disclose

\section{Availability of data and materials}

The datasets used during the current study are available from the corresponding author on reasonable request.

\section{Declarations}

\section{Ethics approval and consent to participate}

The institutional research ethics review committee approved the report (Mansoura University/Faculty of Medicine/ Egypt). IRB reference number is "R.20.06.895". Informed consent from the patient was waived due to the retrospective design of this report.

\section{Consent for publication}

Written informed consent was waived.

\section{Competing interests}

The authors declare that they have no competing interests.

\section{Author details}

${ }^{1}$ Radiology Department, Faculty of Medicine, Mansoura University, Mansoura, Egypt. ${ }^{2}$ Radiology Department, Faculty of Medicine, Urology and Nephrology Center, Mansoura University, El Gomhorea St., Mansoura, Egypt. ${ }^{3}$ Radiology Department, Faculty of Medicine, Student Hospital, Mansoura University, Mansoura, Egypt.

Received: 21 September 2021 Accepted: 21 January 2022 Published online: 02 February 2022

\section{References}

1. Oh SJ, Bae DS, Suh BJ (2015) Synchronous triple primary cancers occurring in the stomach, kidney, and thyroid. Ann Surg Treat Res 88:345-348

2. Kim JE, Lee JM, Baek JH et al (2015) Differentiation of poorly differentiated colorectal adenocarcinomas from well- or moderately differentiated colorectal adenocarcinomas at contrast-enhanced multidetector CT. Abdom Imaging 40(1):1-10. https://doi.org/10.1007/s00261-014-0176-z

3. Waldum HL, Fossmark R (2018) Types of gastric carcinomas. Int J Mol Sci 19(12):4109. https://doi.org/10.3390/ijms19124109

4. El-Badrawy A, Gadelhak B, Helmy EM et al (2020) Multidetector computed tomography evaluation of synchronous lymphoma and other solid malignancies. J Cancer Res Ther 16(1):60-65. https://doi.org/10.4103/jcrt. JCRT_325_17

5. Warren S, Gates O (1932) Multiple primary malignant tumors. Am J Cancer 16:1358-1414

6. Demandante CG, Troyer DA, Miles TP (2003) Multiple primary malignant neoplasms: case report and a comprehensive review of the literature. Am J Clin Oncol 26(1):79-83

7. Shao N, Wang HK, Zhu Y, Ye DW (2018) Modification of American Joint Committee on cancer prognostic groups for renal cell carcinoma. Cancer Med 7:5431-5438
8. Forner A, Reig ME, de Lope CR, Bruix J (2010) Current strategy for staging and treatment: the BCLC update and future prospects. Semin Liver Dis 30:61-74

9. Yun HR, Yi LJ, Cho YK, Park JH, Cho YB, Yun SH et al (2009) Double primary malignancy in colorectal cancer patients-MSI is the useful marker for predicting double primary tumors. Int J Colorectal Dis 24:369-375

10. Mariotto AB, Rowland JH, Ries LA, Scoppa S, Feuer EJ (2007) Multiple cancer prevalence: a growing challenge in long-term survivorship. Cancer Epidemiol Biomarkers Prev 16(3):566-571

11. Maida M, Macaluso FS, Galia M, Cabibbo G (2013) Hepatocellular carcinoma and synchronous liver metastases from colorectal cancer in cirrhosis: a case report. World J Hepatol 5(12):696-700

12. Hayat MJ, Howlader N, Reichman ME, Edwards BK (2007) Cancer statistics, trends, and multiple primary cancer analyses from the Surveillance, Epidemiology, and End Results (SEER) Program. Oncologist 12:20

13. Jeong O, Jung MR, Kang JH, Ryu SY (2020) Prognostic performance of preoperative staging: assessed by using multidetector computed tomography-between the new clinical classification and the pathological classification in the eighth American Joint Committee on Cancer Classification for Gastric Carcinoma. Ann Surg Oncol 27(2):545-551. https:// doi.org/10.1245/s10434-019-07845-3

14. Sheikh MT, Sheikh MT, Jan M, Khan HA, Vashisht GP, Wani ML (2017) Role of multi-detector CT (MDCT) in evaluation of Bowel diseases. J Clin Diagn Res 11(7):TC11-TC13. https://doi.org/10.7860/JCDR/2017/26757.10240

15. Grazzini G, Danti G, Cozzi D et al (2019) Diagnostic imaging of gastrointestinal neuroendocrine tumours (GI-NETs): relationship between MDCT features and 2010 WHO classification. Radiol Med 124(2):94-102. https:// doi.org/10.1007/s11547-018-0946-8

16. Choi JY, Lee JM, Sirlin CB (2014) CT and MR imaging diagnosis and staging of hepatocellular carcinoma: part I. Development, growth, and spread: key pathologic and imaging aspects. Radiology 272:635-654

17. Tang W, Wu N, OuYang H, Haung Y, Liu L, Li M (2015) The presurgical T staging of non-small cell lung cancer: efficacy comparison of 64-MDCT and 3.0 T MRI. Cancer Imaging 15:14

18. Kamel Al, Badawy MH, Elganzoury H, Elkhouly A, Elesaily K, Eldahshan S, Ismail MA et al (2016) Clinical versus pathologic staging of renal tumors: role of multi-detector CT urography. Electron Phys 8(1):1791-1795

19. Moschetta M, Scardapane A, Lorusso V, Rella L, Telegrafo M, Serio G, Angelelli $\mathrm{G}$ et al (2015) Role of multidetector computed tomography in evaluating incidentally detected breast lesions. Tumori 101(4):455-460

20. Schieda N, Al-Dandan O, Shabana W, Flood TA, Malone SC (2015) Is primary tumor detectable in prostatic carcinoma at routine contrastenhanced CT? Clin Imaging 39(4):623-626

21. Tsili AC, Tsampoulas C, Dalkalitsis N, Stefanou D, Paraskevaidis E, Efremidis SC (2008) Local staging of endometrial carcinoma: role of multidetector CT. Eur Radiol 18(5):1043-1048

22. Volpe A (2016) The role of active surveillance of small renal masses. Int J Surg 36:518-524. https://doi.org/10.1016/j.ijsu.2016.06.007

23. Znaor A, Lortet-Tieulent J, Laversanne M, Jemal F (2015) International variations and trends in renal cell carcinoma incidence and mortality. Eur Urol 67(3):519-530. https://doi.org/10.1016/j.eururo.2014.10.002

24. Eom BW, Lee HJ, Yoo MW et al (2008) Synchronous and metachronous cancers in patients with gastric cancer. J Surg Oncol 98:106-110

\section{Publisher's Note}

Springer Nature remains neutral with regard to jurisdictional claims in published maps and institutional affiliations. 